\title{
Echolocation of Central Amazonian 'whispering' phyllostomid bats: call design and interspecific variation
}

\author{
Natalie Yoh ${ }^{1,2}$ (D) $\cdot$ Peter Syme ${ }^{2}$ (D) Ricardo Rocha ${ }^{3,4,5}$ (D) Christoph F. J. Meyer $^{2,3,4}$ (D) Adrià López-Baucells $^{3,4,6}$ (ID
}

Received: 13 September 2019 / Accepted: 30 April 2020 / Published online: 30 May 2020

(C) The Author(s) 2020

\begin{abstract}
Phyllostomids (New World leaf-nosed bats) are the ecologically most diverse bat family and have undergone the most extensive adaptive radiation of any mammalian family. However comprehensive, multi-species studies regarding phyllostomid echolocation are scarce in the literature despite abundant ecological research. In this study, we describe the call structure and interspecific variation in call design of 40 sympatric phyllostomid species from the Central Brazilian Amazon, focussing on general patterns within genera, subfamilies and between feeding guilds. All but one species utilized short, broadband FM calls consisting of multiple harmonics. As reported for other bat families, peak frequency was negatively correlated with body mass and forearm length. Twenty-five species alternated the harmonic of maximum energy, principally between the second and third harmonic. Based on PCA, we were unable to detect any significant differences in echolocation call parameters between genera, subfamilies or different feeding guilds, confirming that acoustic surveys cannot be used to reliably monitor these species. We present Ametrida centurio as an exception to this generalized phyllostomid structure, as it is unique in producing a mono-harmonic call. Finally, we discuss several hypotheses regarding the evolutionary pressures influencing phyllostomid call structure.
\end{abstract}

Keywords Bioacoustics $\cdot$ Chiroptera $\cdot$ Echolocation $\cdot$ Neotropical bats $\cdot$ Phyllostomidae

\section{Introduction}

The family Phyllostomidae is not only the second largest bat family, consisting of approximately 62 extant genera and 219 species, but it also remains unrivalled amongst mammalian families for its ecological and morphological radiation (Rex et al. 2011; Monteiro and Nogueira 2011; Simmons and Cirranello 2019). Intricate partitioning of resources has cultivated

Communicated by: Zuzanna Hałat,

Electronic supplementary material The online version of this article (https://doi.org/10.1007/s13364-020-00503-0) contains supplementary material, which is available to authorized users.

Natalie Yoh

njay2@kent.ac.uk

1 Durrell Institute of Conservation and Ecology, School of Anthropology and Conservation, University of Kent, Canterbury CT2 7NZ, UK

2 Ecosystems and Environment Research Centre, School of Science, Engineering and Environment, University of Salford, Salford M5 4WT, UK sophisticated dietary specialization within the family which includes frugivory, folivory, insectivory, carnivory and nectarivory (Aguirre et al. 2003; Monteiro and Nogueira 2011; Rocha et al. $2017 \mathrm{a}$ ), as well as the only three sanguivorous mammalian species (Zepeda Mendoza et al. 2018).

In the Central Brazilian Amazon, there are at least 84 known species of phyllostomids (López-Baucells et al. 2016). Many of these provide ecosystem services such as
3 Centre for Ecology, Evolution and Environmental Changes, Faculty of Sciences, University of Lisbon, 1749-016 Lisbon, Portugal

4 Biological Dynamics of Forest Fragments Project, National Institute for Amazonian Research and Smithsonian Tropical Research Institute, Manaus 69011-970, Brazil

5 CIBIO/InBIO-UP, Research Centre in Biodiversity and Genetic Resources, University of Porto, Rua Padre Armando Quintas, 4485-661 Vairão, Portugal

6 Natural Sciences Museum of Granollers, 08402 Granollers, Catalonia, Spain 
pollination, seed dispersal and arthropod suppression (Kunz et al. 2011), which are crucial to maintaining ecosystems and habitats that are under ever-increasing pressure from anthropogenic activities. Although mist netting is most often used to survey tropical bats, acoustic methods are being increasingly employed to sample and monitor aerial-hawking insectivorous species. This is due to the fact that acoustic sampling complements traditional capture techniques, which alone are insufficient for fully inventorying local species assemblages (Flaquer et al. 2007; MacSwiney et al. 2008; Pech-Canche et al. 2011; Rydell et al. 2002; Silva and Bernard 2017). The use and capabilities of bioacoustic surveys have advanced greatly over the past few decades (Clement et al. 2014; Deichmann et al. 2018), and sound is now utilized in the research of many taxonomic groups such as birds, amphibians, marine mammals and even plants (Deichmann et al. 2018; Jung et al. 2018). However, this technique has not been commonly applied to phyllostomid species which have been deemed unsuitable candidates for acoustic monitoring (Brinkløv et al. 2009; Fenton et al. 1992).

Whereas aerial-hawking insectivores rely predominantly on echolocation to forage, phyllostomids typically have more sophisticated sight and olfactory senses and have been shown to be less reliant on echolocation to locate food resources (Brinkløv et al. 2011; Korine and Kalko 2005; Fleming 1989). Most phyllostomids produce low-intensity calls (Brinkløv et al. 2009), and how species utilize them for foraging is not fully understood. However, there are several studies suggesting that sound may be an important means by which frugivorous species can quickly discriminate between desired floral species, e.g. fruit, within other vegetation (Brinkløv et al. 2009; Gonzalez-Terrazas et al. 2016; Korine and Kalko 2005). Echolocation call structure (including parameters such as duration, peak frequency, bandwidth and intensity) is closely associated with the affiliation to different types of food resources and the characteristics of the environment in which they are present (Denzinger and Schnitzler 2013). Bats foraging on aerial insects in open areas (e.g. above the canopy) utilize long, low-frequency, quasi-constant frequency (QCF) calls with narrow bandwidths for maximizing prey detection range but which provide minimal environmental information (Denzinger and Schnitzler 2013). In contrast, the majority of bats which glean insects within dense vegetation use either short, broadband, low-intensity frequencymodulated (FM) calls or almost entirely constant-frequency (CF) calls, which maximize environmental information, but attenuate quickly (Jennings et al. 2004; Russo et al. 2018) .

Phyllostomids across different feeding guilds utilize calls of a similar structure, characterized as short, broadband, FM calls consisting of multiple harmonics (Brinkløv et al. 2009; Jennings et al. 2004). Divergence in nose leaf structure has been shown to be linked with dietary specialization within this group (Leiser-Miller and Santana 2020); however, this morphologic variation and the associated variation in call structure is likely limited by phylogenetic constraints (Collen 2012). Therefore, despite their dietary diversity, phyllostomids rely on similar foraging strategies (Giannini and Kalko 2004) - typically gleaning their food from densely cluttered vegetation. The low intensity and high directionality of their echolocation calls make them difficult to record, and most studies to date have focussed on one or few species, leaving many phyllostomid calls undescribed (Arias-Aguilar et al. 2018; Jennings et al. 2004).

These difficulties, and therefore the limited capacity for bioacoustics to be used in their monitoring, have led to a research deficit concerning phyllostomid echolocation. Here, we address this information gap by describing and comparing the echolocation calls of 40 sympatric phyllostomid species (24 genera) from the Central Brazilian Amazon. We describe the interspecific variation within - and between - genera and subfamilies, as well as explore the influence of body size and feeding guild on call structure.

\section{Material and methods}

\section{Study area}

This study was carried out at the Biological Dynamics of Forest Fragments Project (BDFFP) $\sim 80 \mathrm{~km}$ north of Manaus in the Central Amazon $\left(2^{\circ} 20^{\prime} \mathrm{S}, 60^{\circ} 6^{\prime} \mathrm{W} ; 80\right.$ $160 \mathrm{~m}$ a.s.l.), Brazil. This reserve was established in the 1980 s, with the main goal to investigate the effects of forest fragment size on Neotropical biota (Bierregaard and Lovejoy 1990). To do so, fragments of 1,10 and 100 ha were isolated from continuous terra firme rainforest by distances of 80 $650 \mathrm{~m}$. Fragments are nowadays surrounded by a matrix of secondary forest at varying successional stages (Carreiras et al. 2014). Primary forest reaches $30-37 \mathrm{~m}$ in mean canopy height, with isolated trees up to $55 \mathrm{~m}$ tall (Laurance et al. 2011). Rainfall varies from 1900 to $3500 \mathrm{~mm}$ annually, with a dry season between July and November and a rainy season between November and June (Ferreira et al. 2017).

\section{Mist netting}

Capture sessions were carried out between August 2011 and October 2014, using both ground- and canopy- level mist nets placed in a variety of habitats: continuous primary forest, forest fragments and secondary forest in which standardized surveys were conducted and temporary lakes, rivers, streams and clearings where we sampled opportunistically (Farneda et al. 2015; Silva et al. 2020; Rocha et al. 2019; Torrent et al. 2018). Mist nets were exposed for six continuous hours after sunset. We identified all individuals using available field guides and morphological keys (López-Baucells et al. 2016). Taxonomy 
follows López-Baucells et al. (2016) except for Mimon crenulatum and Lonchophylla thomasi, which are referred to as Gardnerycteris crenulatum and Hsunycteris thomasi respectively (Parlos et al. 2014; Hurtado et al. 2014). Standard morphological measurements (including forearm length and body mass) and demographic data were collected following Handley et al. (1991). Details relating to the habitat characteristics of where species were captured (e.g. vertical stratum) can be sourced from Farneda et al. (2015), Silva et al. (2020), Rocha et al. (2019) and Torrent et al. (2018).

\section{Sound recordings}

Bats were recorded with a Pettersson D1000X bat detector (Pettersson Elektronik, Sweden) upon hand release. The detector was set to full spectrum, continuous recording (no trigger) and a sampling rate of $384 \mathrm{kHz}$. The detector was placed 5-10 $\mathrm{m}$ from the point of release (depending on the species), and once alight, we followed the bat's flight path for as long as possible.

\section{Acoustic measurements}

Sound files were analysed using Kaleidoscope V4.0.4 (Wildlife Acoustics, USA). Sound files consisting of lowquality recordings, or those with multiple species present, were discarded. Moreover, we discarded pulses recorded just after release due to the obvious stress signature (see Supplementary Fig. A.1). For each of the remaining files, ten pulses were identified for analysis. This was not possible for six species which had limited recordings (Table 1). In these cases, the maximum number of pulses obtained was analysed. Measurements were extracted from each of these pulses for six acoustic parameters on each harmonic present: the frequency of maximum energy (peak frequency), the frequency at the start of the harmonic (start freq.), the frequency where the harmonic ends (end freq.), the maximum frequency detected within a harmonic (maximum freq.), the minimum frequency detected within a harmonic (minimum frequency) and the duration in milliseconds between the start and end frequencies (pulse duration) (Fig. 1). Peak frequency was determined from the power spectrum, whereas other variables were measured manually from the spectrogram plots by comparing intensity. Maximum and minimum frequency and start and end frequency were considered $20 \mathrm{~dB}$ below peak. Furthermore, the peak frequency across harmonics was compared within each pulse to identify the harmonic of maximum energy. Kaleidoscope settings were as follows: FFT size 256, window size 128 and cache size $256 \mathrm{MB}$.

Due to pulse overlap, associated with the multi-harmonic nature of the echolocation calls produced by the species targeted by this study, it was neither possible to use an automated pulse-measuring software (e.g. Scan'R) nor to discern call parameters such as start/end frequency and duration from the oscillogram. Although these approaches are preferable for measuring call characteristics as they reduce variability due to the analyst's bias present when parameters are measured via a sonogram, we believe that our methodology was well suited for our purposes and that any potential variability in the measurements did not substantially affect the conclusions drawn here. However, the call measurements we present here should be viewed in light of these measuring limitations.

\section{Statistical analysis}

Linear regression analysis, performed in R 3.4.4 (R Core Team 2018), was used to assess the relationship between body size and peak frequency. For this, the peak frequency of the third harmonic was regressed against the species' mean body mass and forearm length. The analysis was restricted to 23 species for which we had body mass and forearm length data based on our mist net captures. The third harmonic was used as it was the predominant harmonic of maximum energy for 22 of the 38 species included in the analysis. No echolocation calls of sufficient quality were obtained for Lophostoma schulzi. Therefore, it was excluded from the analysis, and the regression was performed for 22 species.

Principal component analysis (PCA) was conducted on the aforementioned call parameters measured on the third harmonic of each species' calls, using the R package 'stats', to summarize and visualize the similarity in echolocation call structure of all subfamilies. Log call variables were zero centred and were scaled to have unit variance.

\section{Results}

\section{Call descriptions}

Across the study period, 40 phyllostomid species from five subfamilies were captured. Acoustic analysis was conducted using a total of 2112 pulses from 135 individuals (Table 1). Sonograms were produced for all species except Lophostoma schulzi, as no representative release echolocation call of sufficient quality was obtained for this species. All species, apart from Ametrida centurio, produced multi-harmonic calls which were visible on the raw recordings. These were characterized as broadband, downward-sweeping, frequency-modulated calls with overlapping harmonic components. The frequency of maximum energy was almost exclusively located either in the second or third harmonic (88\% of all recorded pulses). They also provided the best quality calls for analysis. Harmonics higher than the third were rare and were considered the harmonic of maximum energy for only $2 \%$ of recorded pulses. Moreover, these harmonics were extremely faint or corrupted (e.g. higher harmonics were 


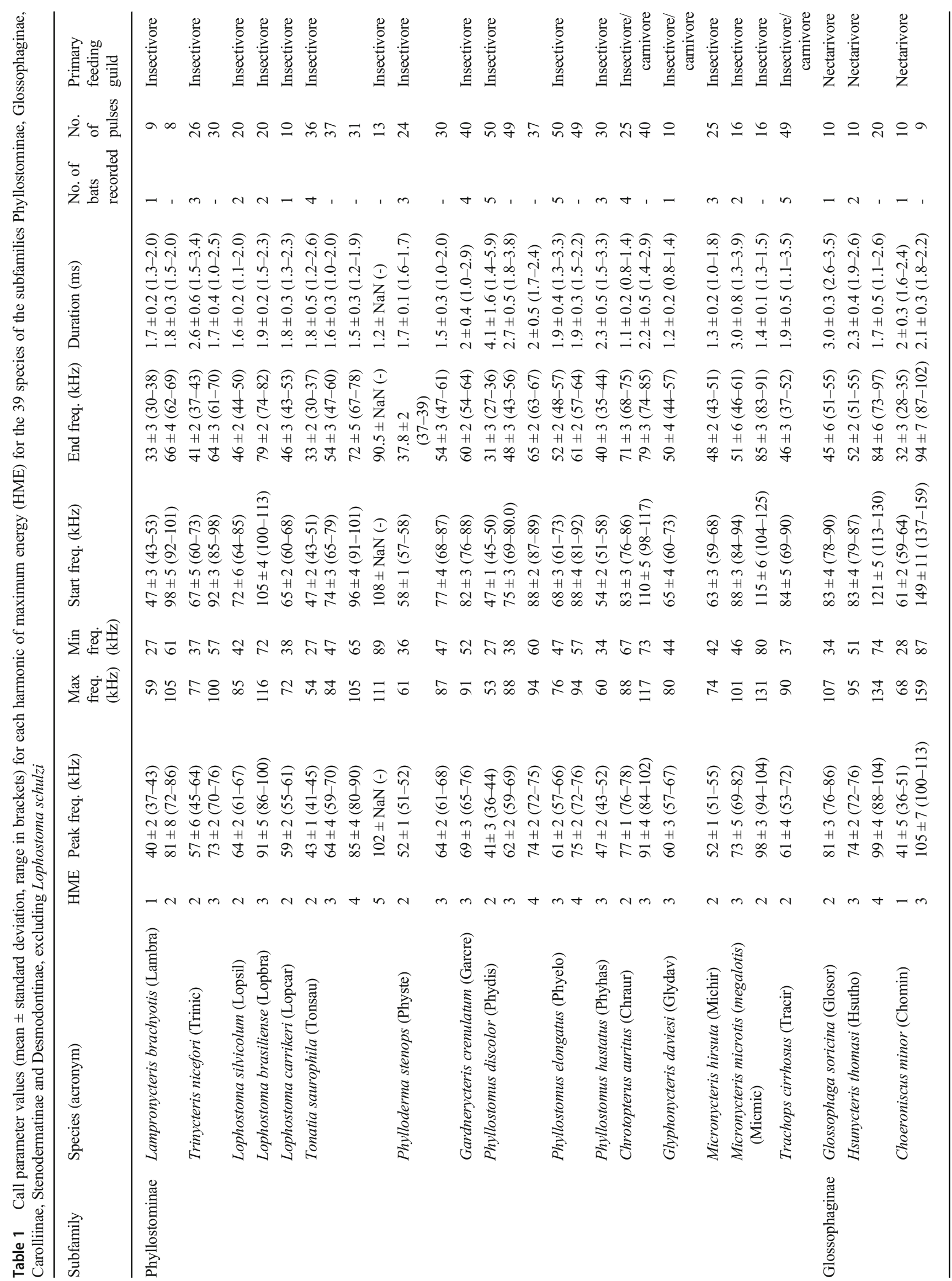




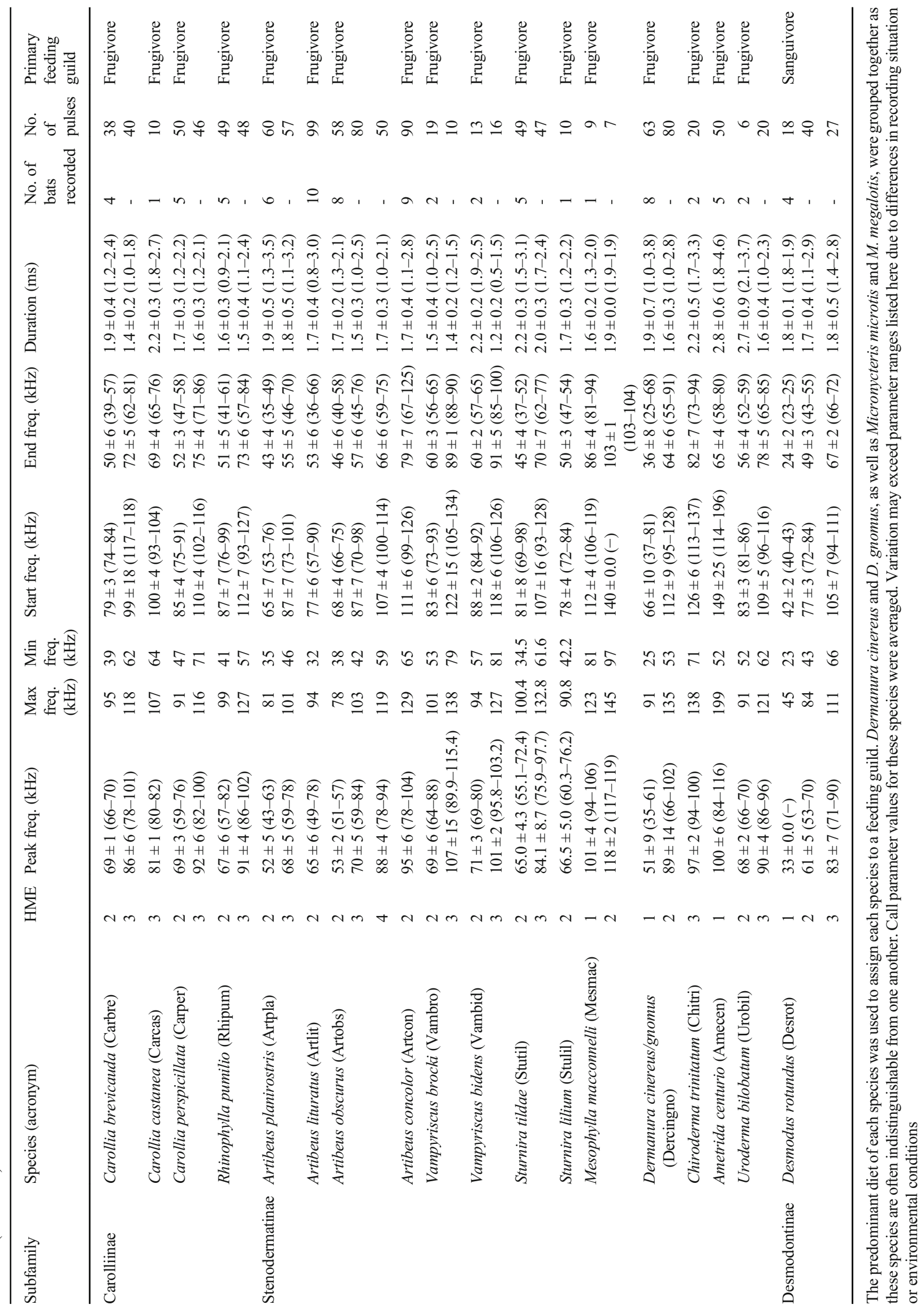




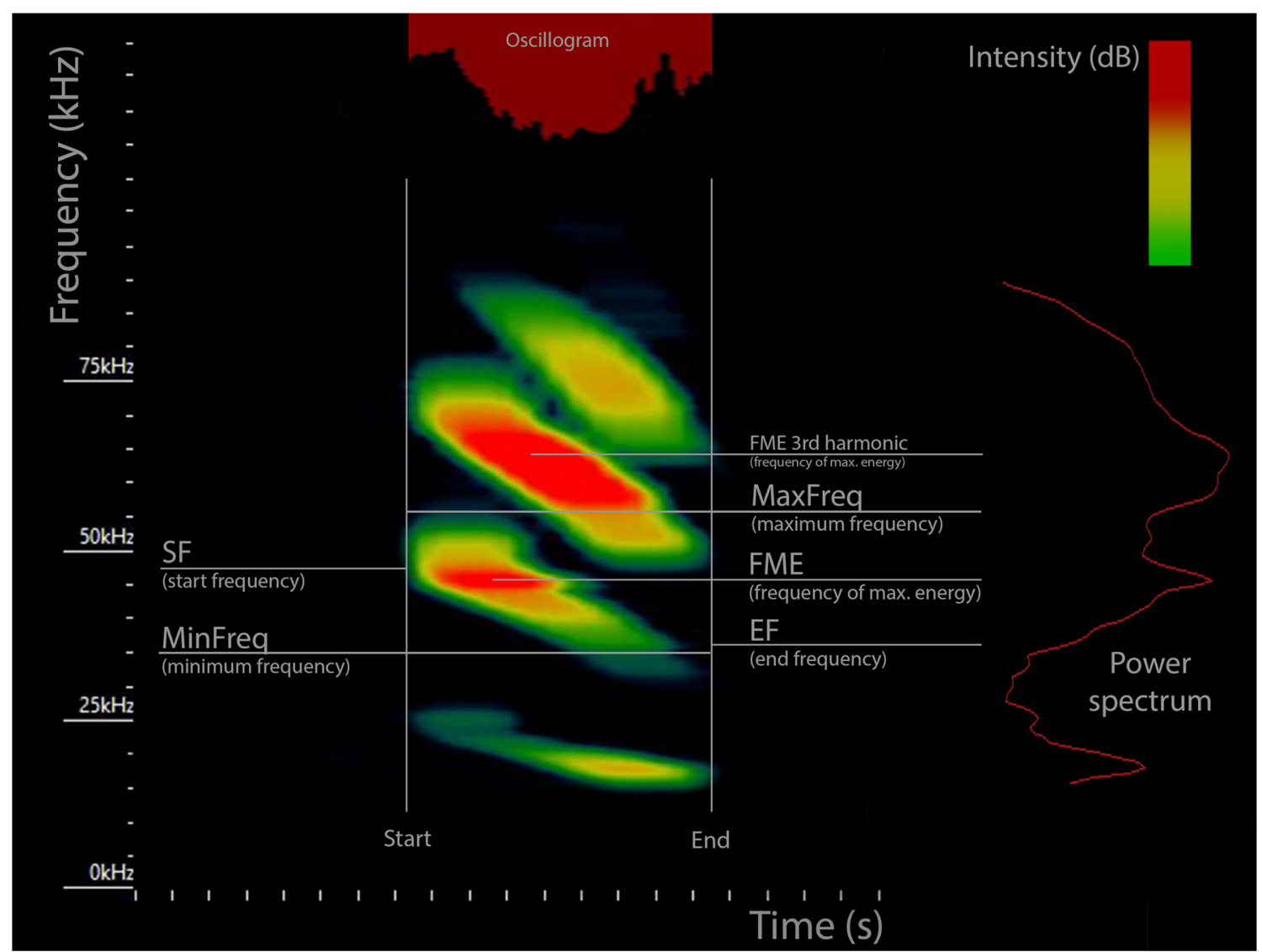

Fig. 1 Illustration of the points of measurement for call parameters used in this study in Kaleidoscope, including Phyllostomus discolor call. Peak frequency (FME) was measured from the power spectrum, whereas the other parameters were measured from the sonogram. FFT size 5112 and win size 128

reflective of relative body size as the largest of the three species examined; L. silvicolum utilized lower frequency calls than the smaller L. brasiliense and L. carrikeri (Table 1).

Body size was also negatively correlated with call frequency overall in the genus Phyllostomus. Despite being the largest species examined in this study, Chrotopterus auritus utilized calls that were higher in frequency than predicted for its body size (see Fig. 2 and Table 1).

\section{Stenodermatinae}

A total of 15 stenodermatids were captured during the study period. There was very little variation in the echolocation calls of Artibeus planirostris, A. lituratus and A. obscurus - all produced calls with similar peak frequencies of $\sim 70 \mathrm{kHz}$ on the harmonic of maximum energy (Fig. 3). Artibeus concolor (the smallest Artibeus examined during this study) emitted calls of comparatively higher frequencies than the larger congenerics. However, an overlap occurred between the third harmonic of $A$. planirostris and A. obscurus and the second harmonic of the largest species, A. lituratus. Because of the overlap between the frequencies of 


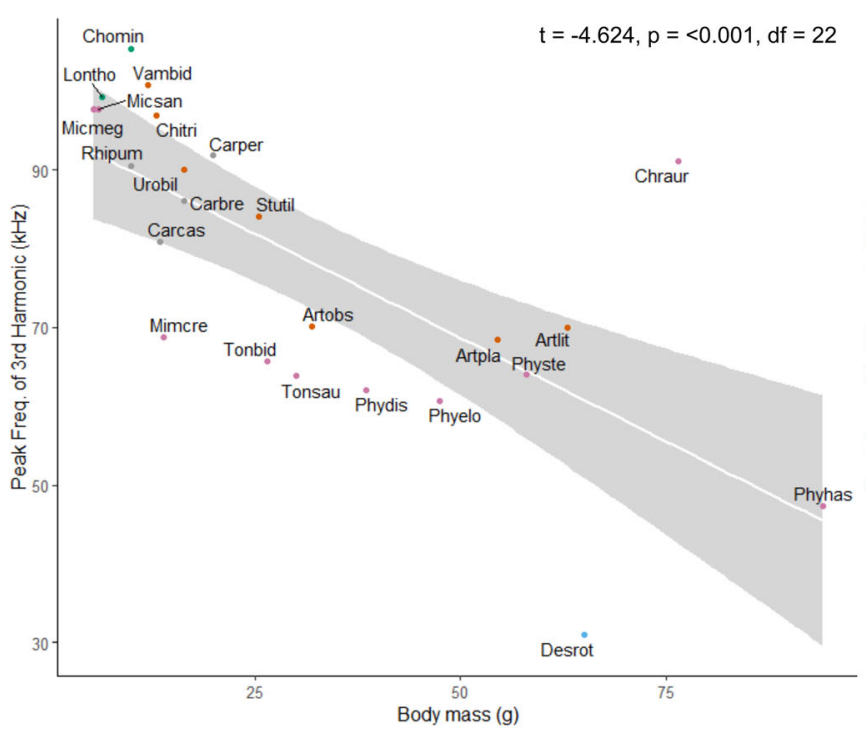

Fig. 2 Relationship between body size, represented by body mass and forearm length, and mean peak frequency of the third harmonic. The third harmonic was used as it was the predominant harmonic of maximum

multiple harmonics, it is not possible to reliably distinguish between these species. The genera Sturnira and Vampyriscus produce calls that are indistinguishable and exhibit high similarity with the calls of Dermanura. There is a high degree of overlap between the different harmonics amongst this group (Table 1). The shortest bandwidths and highest frequencies are observed in the smaller species Platyrrhinus helleri and Mesophylla macconnelli. The species of these six genera produce calls similar to those present in other phyllostomid families. Ametrida is a monotypic genus consisting of A. centurio. Pulses are frequencymodulated resembling an inverted hockey stick shape, broad bandwidths and short durations. The species shows a high degree of variability within call frequencies (Table 1), particularly concerning the call start and end frequencies. It is also one of the few phyllostomid species to not emit a multi-harmonic call. This, combined with its high peak and maximum frequencies, enables A. centurio to be identified using acoustic analysis. Uroderma bilobatum also exhibits high frequency calls but overlaps with several species from other genera.

\section{Desmodontinae}

Desmodontinae is a monophyletic group comprising the species Desmodus rotundus, Diaemus youngi and Diphylla ecaudata. However, only D. rotundus was captured in this study. This species exhibited frequencies of maximum energy on each of the first three of the four visible harmonics (Table 1) and utilized low-frequency

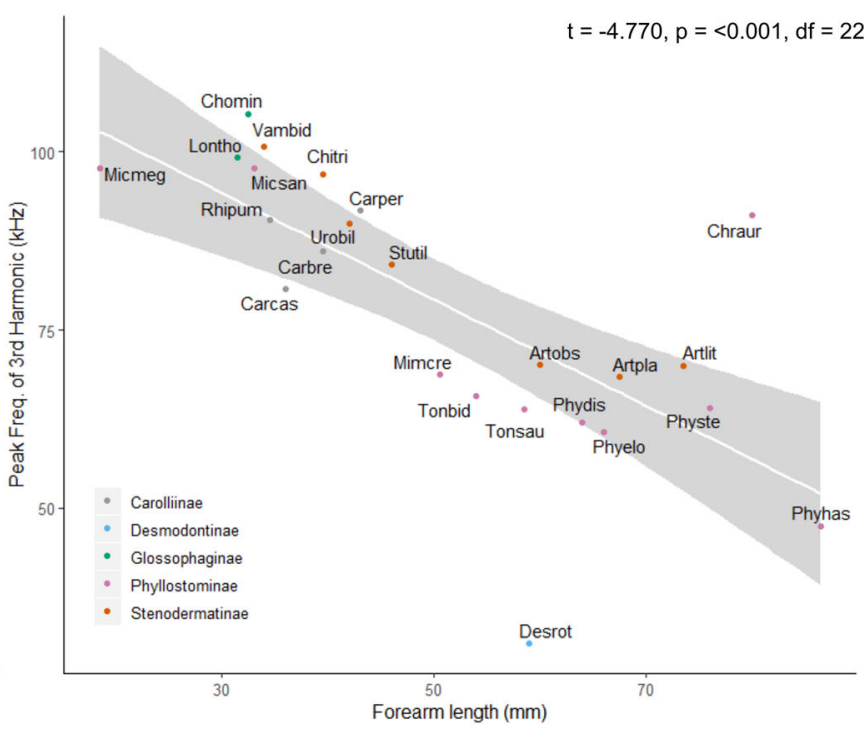

energy across the species list. Line shows the results of a linear regression for each plot. See Table 1 for species abbreviations. Grey represents $95 \%$ confidence level interval

calls for its body size. Calls produced by this species are typical of other phyllostomids in terms of their structure.

\section{Carolliinae}

Four species from two genera of the subfamily Carolliinae were captured. Although morphologically similar to the smallest species of the genus Carollia (C. castanea), Rhinophylla pumilio exhibited call frequencies similar to the largest species-C. perspicillata (Table 1). Call shape was similar across both genera (Fig. 3) and to that of other phyllostomids. Between Carollia species, frequencies reflected their relative body sizes, with larger species emitting echolocation calls of lower frequency.

\section{Glossophaginae}

Three species from three genera of the subfamily Glossophaginae were captured during the study. Unlike other subfamilies, glossophagines appear to exhibit variation in call shape amongst genera. Glossophaga soricina restricts the frequency of maximum energy to the second harmonic, utilized broader bandwidths and produced a distinctively longer call compared with all other phyllostomid species (Table 1). Choeroniscus minor exhibited frequencies of maximum energy on the first and third harmonic which were not expressed on the second harmonic. 


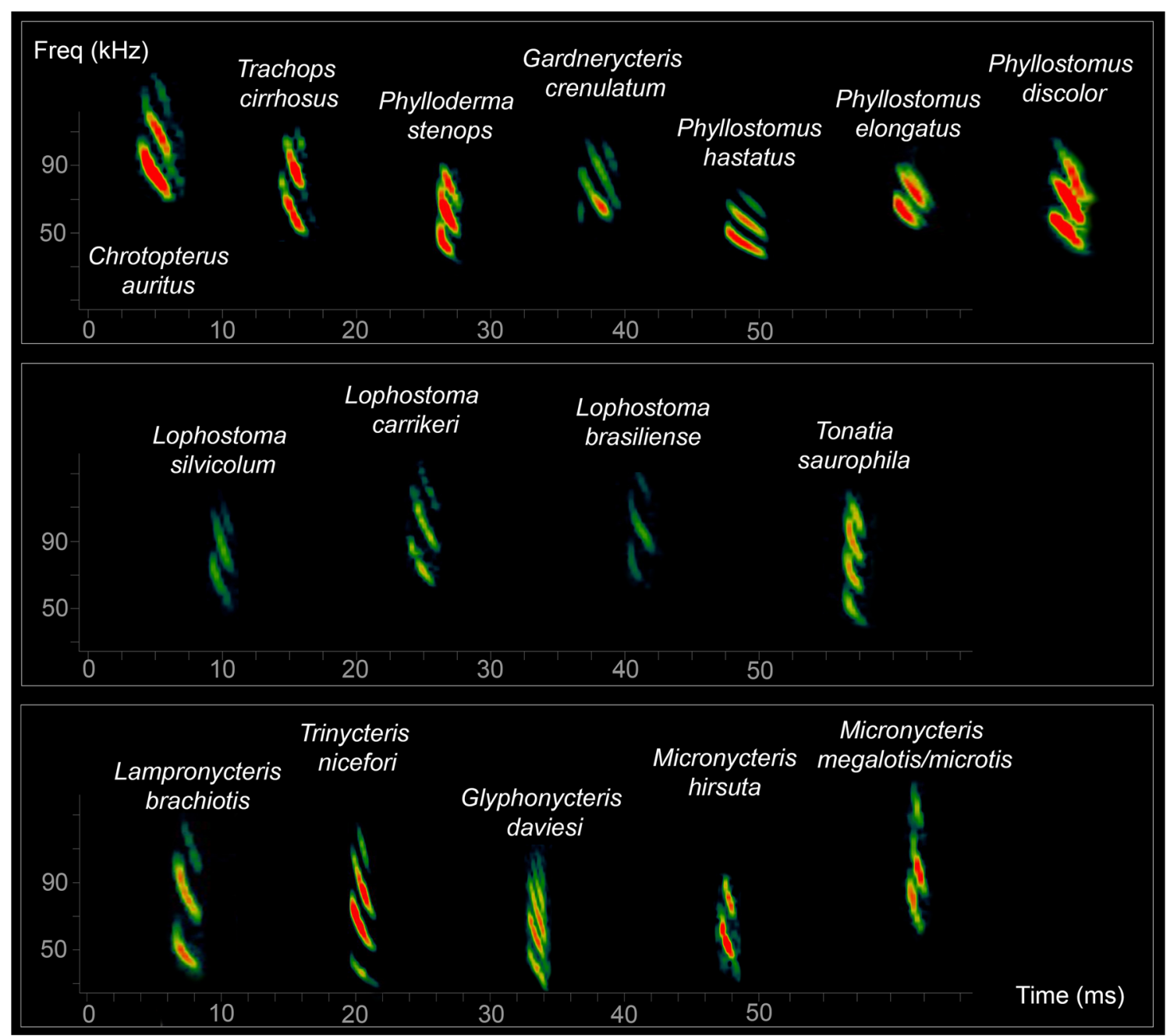

Fig. 3 Echolocation call design of 16 species (11 genera) from the subfamily Phyllostominae. Lophostoma schulzi is not included in this figure due to lack of a high-quality sonogram image. Micronycteris megalotis and M. microtis have been joined due to the difficulty in distinguishing between these two species. Call duration and frequency have been scaled to allow comparison between species. Sonogram image is for illustrative purposes and should not be used in isolation for species identification. Call amplitude represented here is not standardized between species and therefore should not be used as a diagnostic feature

\section{Call parameter overlap between phyllostomid subfamilies}

When all species were considered together, no differentiation in call structure between subfamilies was perceivable (Fig. 5).

Across the five subfamilies, Stenodermatinae and Phyllostominae exhibited the largest variation in call structure amongst species.

Multiple species within and between phyllostomid subfamilies show substantial variation in peak frequency, such as A. lituratus, Sturnira tildae and Vampyriscus brocki (Fig. 6). However, despite the substantial difference between peak frequencies of certain species, almost every species has a large overlap in peak frequency range with multiple other species. The only exception to this is $P$. hastatus, which does not exhibit any overlap in peak frequency range of the third harmonic with any other study species.

\section{Discussion}

Our results demonstrate that phyllostomid subfamilies exhibit remarkably similar call structures even when belonging to different feeding guilds. Due to the high degree of overlap in call parameters as revealed by the PCA (Fig. 5), our results corroborate that it is not currently possible to reliably distinguish between most species, genera and subfamilies, based solely on the call parameters used in this study. The total frequency range observed (considering the peak frequencies for all harmonics of maximum energy) ranged from $33.4 \mathrm{kHz}$ (Desmodus rotundus) to $118.2 \mathrm{kHz}$ (Mesophylla macconnelli). Although some differences between certain subfamilies can be observed (Fig. 6), due to the continuous overlap along the gradient of all species, it is not possible to use acoustic data to reliably identify species or subfamilies. 


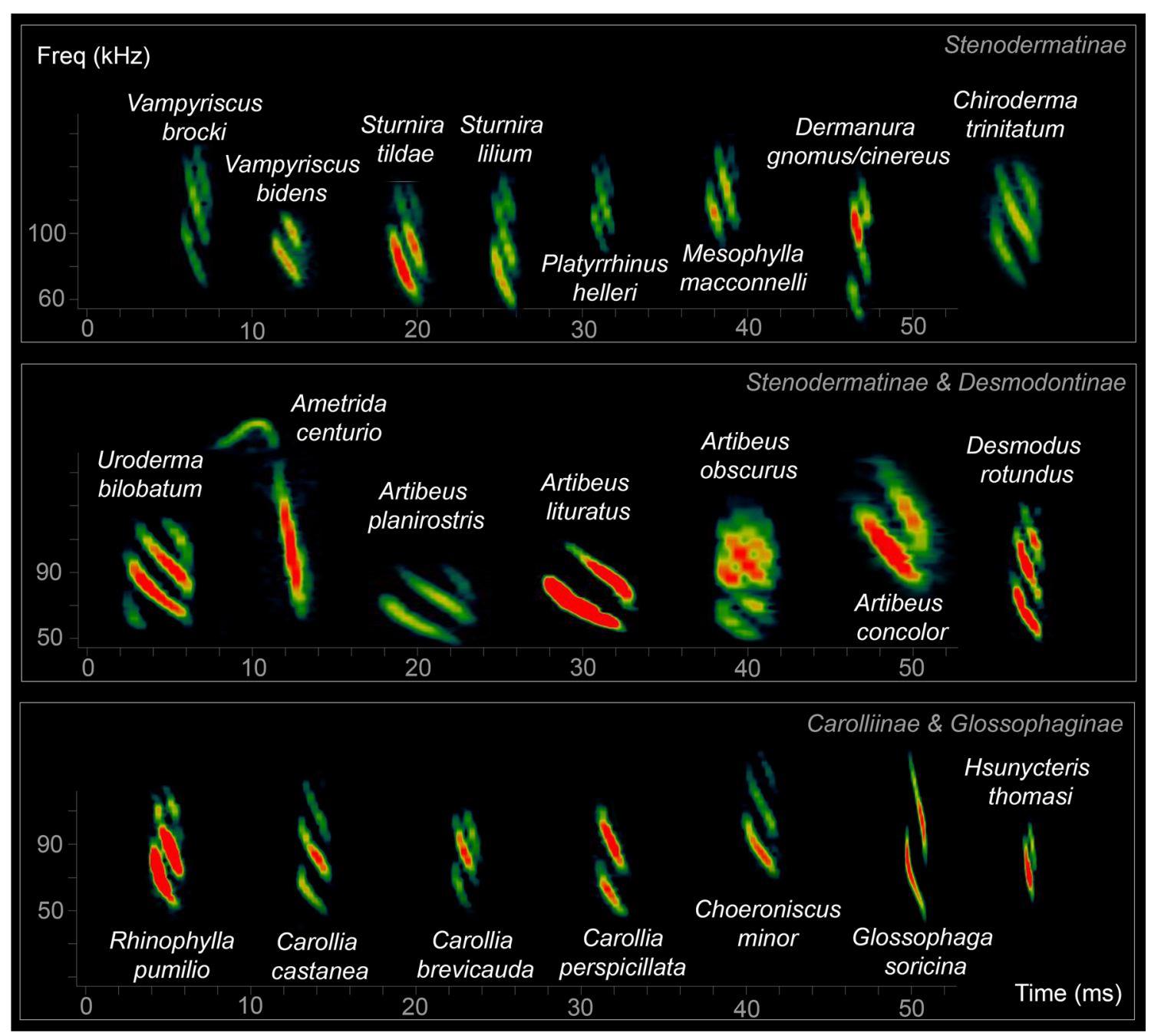

Fig. 4 Echolocation call design of 23 species (15 genera) from the subfamilies Stenodermatinae, Desmodontinae, Carolliinae and Glossophaginae. Dermanura gnomus and D. cinereus are presented together due to the difficulty in distinguishing between these two species. Call duration and frequency have been scaled to allow

\section{Evolutionary advantage for multi-harmonic calls}

All but one species (Ametrida centurio) produced pulses with multiple harmonic components, the majority of which showed a high degree of spectral overlap. By doing so, the production of frequency-modulated calls which extend their bandwidth possibly enables individuals to perceive a more complete representation of their environment than otherwise possible (Altringham 2011; Krumbholz and Schmidt 2001). This includes providing information on shape, size and texture of neighbouring vegetation. However, as they produce low-intensity calls, detection range is limited.

Phyllostomids are not unique in their use of low-intensity, multi-harmonic calls. The families Nycteridae and Megadermatidae not only exhibit convergent evolution in terms of call structure, but they also possess similarities comparison between species. Sonogram image is for illustrative purposes and should not be used in isolation for species identification. Call amplitude represented here is not standardized between species and therefore should not be used as a diagnostic feature

with phyllostomids concerning nose structure and foraging strategies (see Fig. 7) (Altringham 2011; Marimuthu et al. 2010; Schaer et al. 2015). Therefore, similar ecological pressures have resulted in similar evolutionary adaptations in both New and Old World species. By comparing wider groups of species assemblages, future research may be able to uncover the determining factors dictating call characteristics. In doing so, this would improve our understanding of the functionality of these characteristics and their purpose and-more broadly-expand our insights into sound ecology.

\section{Species-specific exceptions to the general phyllostomid call structure}

The phyllostomine Ametrida centurio was the only species which did not produce a multi-harmonic call, which is 


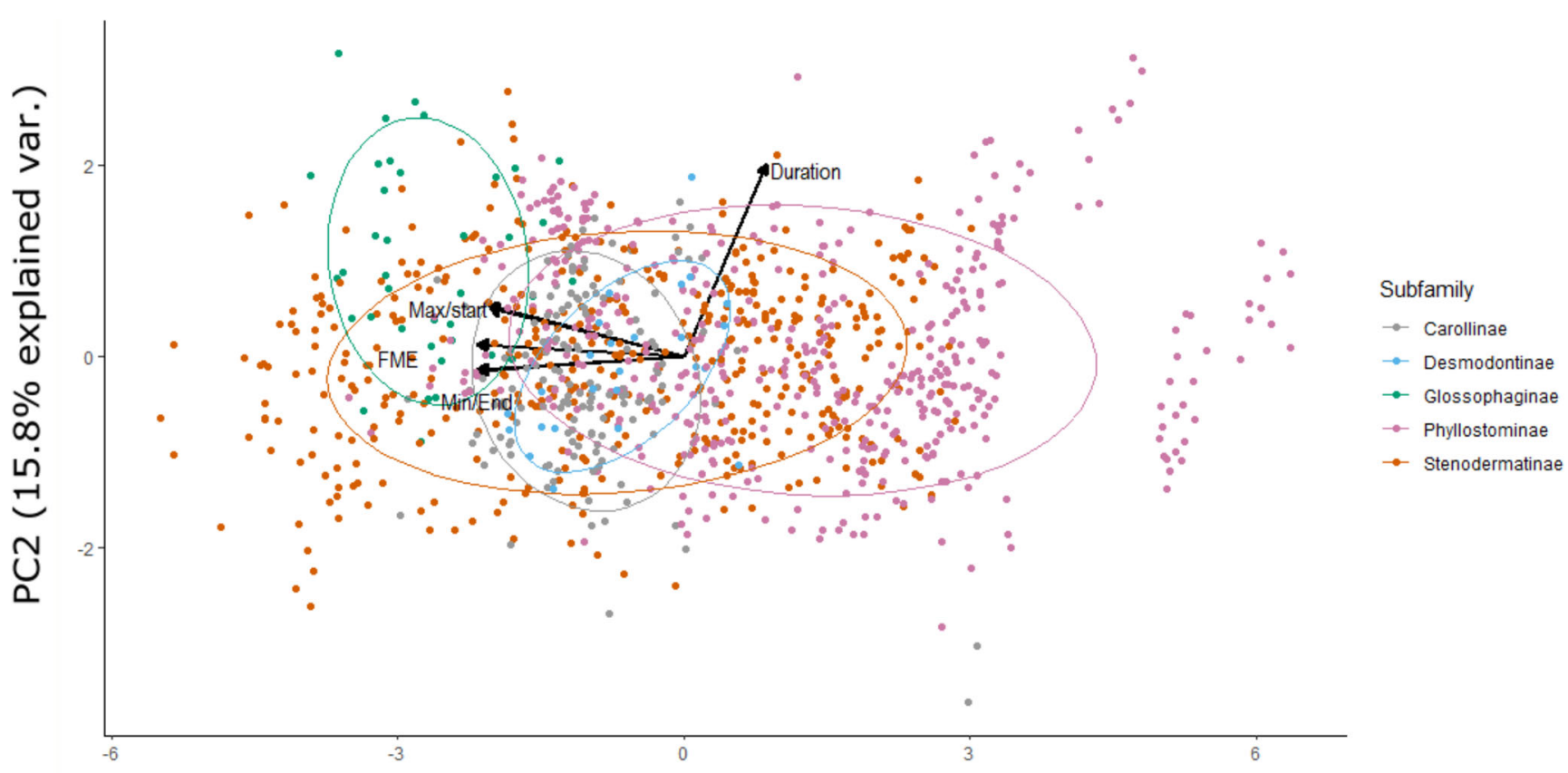

PC1 (78.0\% explained var.)

\begin{tabular}{lrrrrrr}
\hline & PC1 & PC2 & PC3 & PC4 & PC5 & PC6 \\
\hline FME & 0.460581 & 0.130894 & -0.45949 & 0.714037 & 0.218864 & 0.042995 \\
Start Freq. & -0.15862 & 0.649934 & 0.169451 & 0.130625 & 0.014493 & -0.71165 \\
End Freq. & 0.592535 & 0.066552 & 0.315993 & 0.035159 & -0.73713 & -0.00461 \\
Max Freq. & -0.17517 & 0.63635 & 0.249755 & 0.107422 & 0.024455 & 0.699898 \\
Min Freq. & 0.553769 & 0.016274 & 0.472728 & -0.24965 & 0.63753 & -0.02885 \\
Duration & 0.272511 & 0.388351 & -0.61193 & -0.63086 & -0.03849 & 0.031648 \\
& & & & & & \\
SD (+/-) & 1.423248 & 1.319338 & 0.922041 & 0.820333 & 0.599624 & 0.5925 \\
\hline
\end{tabular}

Fig. 5 Arrangement of the 38 phyllostomid species, excluding L. schulzi, according to call parameters of the third harmonic along the axes of a principal component analysis. Circles represent 0.68 confidence ellipse

consistent with previous reports (Collen 2012). Ametrida centurio is considered to be a canopy species which is also associated with forest clearings and waterways (Lee and Dominguez 2000; Rocha et al. 2017b; Silva et al. 2020). It is primarily frugivorous and nectarivorous and favours less cluttered spaces (Lee and Dominguez 2000; Vilar et al. 2015). Being the smallest phyllostomid, it has fewer requirements in terms of manoeuvrability than larger bats (Altringham 2011). It is thus possible that the production of calls with singular harmonics reflects its habitat preferences. Ametrida centurio also expressed large variation in call frequency. This could also be a response to environmental requirements and can also be associated with sexual dimorphism in body size (Lee and Dominguez 2000). Further studies which differentiate between the calls of males and females could test this hypothesis. Research regarding the ecology and biology of this species is limited, in part due to its rarity across probabilities. FME, frequency of maximum energy (peak frequency). Legend includes variable loadings

its range as well as difficulties in surveying it (Vilar et al. 2015). Due to the unique nature of this species' echolocation, records of occurrence may emerge through future canopy surveys utilizing bioacoustics, subsequently improving our understanding of its ecological requirements. Although not present in our study area, Lonchorhina aurita represents another species from the subfamily Phyllostominae whose call Gessinger et al. (2019) recently demonstrated to differ fundamentally from the stereotypical echolocation call design of the family, likely reflecting an adaptation to aerial hawking.

\section{Acoustic partitioning}

Due to the degree of overlap between the echolocation call parameters of phyllostomid species, reliably distinguishing between subfamilies, genera and species is impossible using parameters adopted in this study, with few exceptions such as 


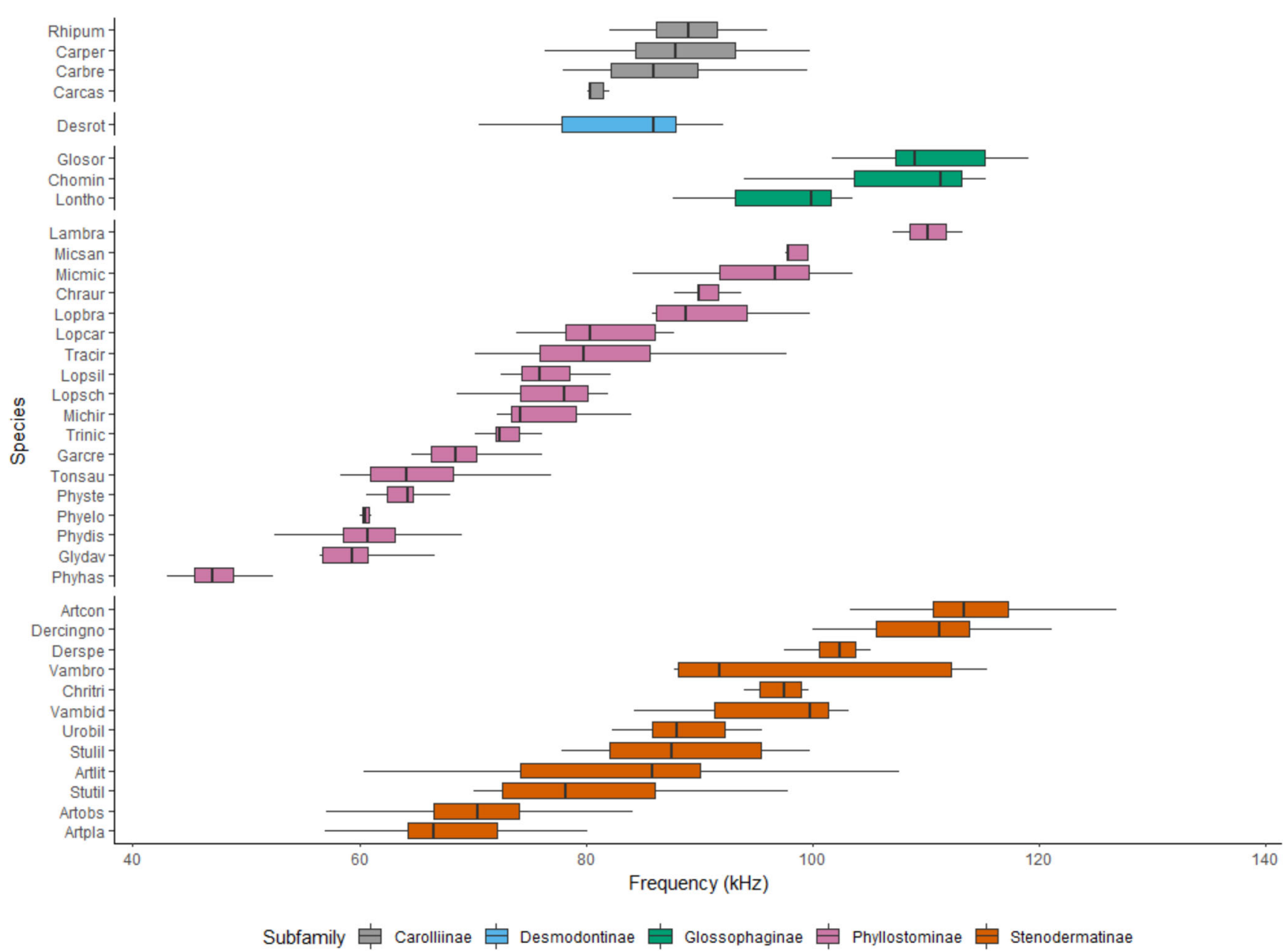

Fig. 6 Peak frequencies observed for the third harmonic of 38 species of the subfamilies Carolliinae, Desmodontinae, Glossophaginae, Phyllostominae and Stenodermatinae. See Table 1 for species abbreviations

A. centurio, P. hastatus and L. aurita. In order to be able to exploit multiple resources, most phyllostomids exhibit a generalist call structure. This allows them to adapt their calls to suit the wide array of environmental conditions encountered and feeding resources exploited (Brinkløv et al. 2009; Fenton et al. 1992; Pio et al. 2010). Nevertheless, substantial differences in peak frequencies distributed across a continuous gradient of variation are evident. Acoustic partitioning between species is usually related to niche differences such as habitat preference and prey selection or to facilitate intraspecific communication (Brinkløv et al. 2009; Denzinger et al. 2018; Denzinger and Schnitzler 2013; Jones and Barlow 2004; Shi et al. 2009). Although multiple feeding guilds were examined in this study, all species considered are gleaners that forage in high-clutter situations and hence utilize broadly similar foraging strategies (Giannini and Kalko 2004). The majority of these species have flexible diets, demonstrating omnivorous selection in response to conditions such as seasonal fluctuations in resource availability (Giannini and Kalko 2004; Santana et al. 2011; Wilkinson and Wenrick Boughman 1998).
Body size is a strong predictor of call frequency for echolocating bat species (see Fig. 2) (Altringham 2011; Jones 1999; Shi et al. 2009). However, this relationship is not consistent amongst phyllostomids (Jones 1999; Russo et al. 2018), and several deviations from this pattern were evident in our data. Although both $C$. auritus and $D$. rotundus produce calls which follow the basic phyllostomid structure (low-intensity, multi-harmonic), it is possible that more specialized diets result in increased selection pressures on acoustic parameters, as observed in L. aurita (Gessinger et al. 2019). D. rotundus utilized frequencies lower than expected relative to its body size (see Table 1). This is likely due to its unique feeding habits, but whether this is related to foraging strategy or prey type remains unclear. Variation in foraging strategy amongst different species has been observed to affect call structure (Altringham 2011; Denzinger and Schnitzler 2013). However, the vast majority of studies relate to aerial insectivores (but see Halfwerk et al. 2014). D. rotundus has an extended forearm length relative to species of the same weight (Altenbach 1979) as it uses its forearm for approaching prey on the ground. It is therefore 

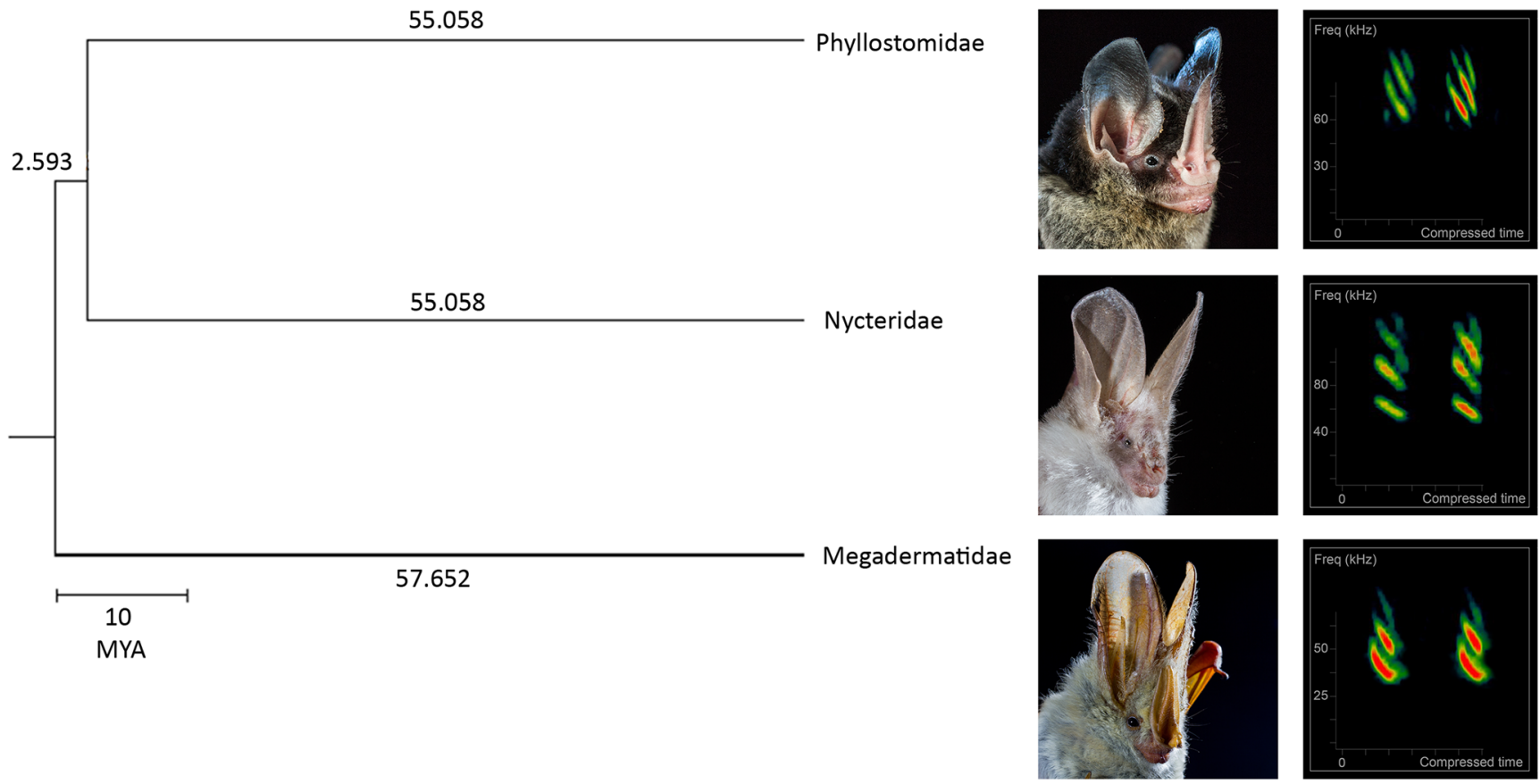

Fig. 7 Despite Phyllostomidae, Nycteridae and Megadermatidae only sharing a common ancestor over 55 million years ago, each family has independently evolved complex nose structures and multi-harmonic calls, a clear example of convergent evolution. Examples of a species call from each family: a Gardnerycteris crenulatum (Phyllostomidae), b Nycteris

possible that the frequencies are not low but rather the forearm is relatively oversized. However, this hypothesis appears unlikely as $D$. rotundus still exhibits low-frequency calls when this variable is excluded from analysis. Another possible explanation for this lies in the fact that $D$. rotundus does not echolocate when approaching prey, its main use thus being navigation during commuting (Schmidt and Schmidt 1977). A high wing loading for long-distance commuting to find mammalian prey (Wilkinson 1985) supports the theory for a competitive advantage in producing decreased call frequencies (Altringham 1996). In contrast, C. auritus exhibited a higher than predicted call frequency relative to its body size (see Table 1) despite gleaning its prey. This species, unlike other large carnivorous bats such as Trachops cirrhosus, feeds almost exclusively on vertebrates (Smith 2008; Wilkinson and Wenrick Boughman 1998). Echolocating at lower frequencies may increase the likelihood of being detected by mammalian prey, hence the higher frequency echolocation observed (Norberg and Fenton 1988).

\section{Study limitations}

O'Farrell et al. (1999) showed that bat echolocation calls recorded shortly after hand release are similar to those recorded from bats emerging from roosts. However, phyllostomid bats usually emit highly modulated pulses of short ranges, and therefore the effect of handling should not be as severe as in thebaica (Nycteridae) and c Lavia frons (Megadermatidae) (b and c were recorded by Adrià López-Baucells in Sibiloi National Park, Kenya). Numbers on branches indicate the amount of time passed since the previous speciation event in millions of years. Phylogenetic reconstruction pruned from Shi and Rabosky (2015)

other aerial insectivorous bats with narrow-band calls. For this study, we minimized this potential bias by only considering pulses recorded at a distance greater than $5 \mathrm{~m}$ away from the point of release and, whenever possible, only when the released bat started circling around it. Although the initial screening process ensured maximum quality of acoustic recordings, this reduced the number of recordings available for analysis. Thus, the number of recordings for several less common species (e.g. A. caudifer) was relatively small compared with more commonly captured species (e.g. A. lituratus) (Table 1).

\section{Conclusion}

In this study we have aimed to both expand and update current knowledge regarding phyllostomid echolocation call design. It is clear that due to the considerable overlap between phyllostomid call parameters, live-trapping still provides the best method for surveying these species. However, future technological developments may allow minute differences in the echolocation call designs of phyllostomid bats to be distinguished from one another and thus allow these species to be monitored using remote sensing techniques.

Acknowledgements We would like to thank the BDFFP for logistical support and the many colleagues, volunteers and field assistants that 
helped collecting data: Jorge M. Palmeirim, Fábio Z. Farneda, Oriol Massana, Diogo F. Ferreira, Marta Acácio, Gilberto Fernandez, Milou Groenenberg, Rodrigo Marciente, Madalena Boto, Inês, Julia Treitler, Solange Farias, Ubirajara Capaverde Jr., Alaércio Reis, Luiz Queiroz, Josimar Menezes, Osmaildo Silva and José Tenaçol. Paulo E.D. Bobrowiec also helped with fieldwork and provided logistic support.

Funding information This work was supported by the Portuguese Foundation for Science and Technology under research grant PTDC/BIABIC/111184/2009 (C.F.J.M.) and scholarships SFRH/BD/ 80488/2011 (R.R.), PD/BD/52597/2014 (A.L.B.) and NE/L002582/1 (N.Y.). Additional funding was provided by the Bat Conservation International to A.L.B. and R.R and by ARDITI-Madeira's Regional Agency for the Development of Research, Technology and Innovation (grant M1420-09-5369-FSE-000002)- to R.R. This is publication 787 in the Technical Series of the BDFFP.

\section{Compliance with ethical standards}

Human and animal rights and informed consent All applicable international, national and/or institutional guidelines for the care and use of animals were followed. All procedures performed in studies involving animals were in accordance with the ethical standards of the institution or practice at which the studies were conducted (Instituto Chico Mendes de Conservação da Biodiversidade (ICMBio) under permit 26877-2).

Open Access This article is licensed under a Creative Commons Attribution 4.0 International License, which permits use, sharing, adaptation, distribution and reproduction in any medium or format, as long as you give appropriate credit to the original author(s) and the source, provide a link to the Creative Commons licence, and indicate if changes were made. The images or other third party material in this article are included in the article's Creative Commons licence, unless indicated otherwise in a credit line to the material. If material is not included in the article's Creative Commons licence and your intended use is not permitted by statutory regulation or exceeds the permitted use, you will need to obtain permission directly from the copyright holder. To view a copy of this licence, visit http://creativecommons.org/licenses/by/4.0/.

\section{References}

Aguirre LF, Herrel A, Van Damme R, Matthysen E (2003) The implications of food hardness for diet in bats. Funct Ecol 17:201-212. https://doi.org/10.1046/j.1365-2435.2003.00721.x

Altenbach JS (1979) Locomotor morphology of the vampire bat Desmodus rotundus. Spec Publs Am Soc Mamm 6:1-137

Altringham JD (1996) Bats: biology and behaviour. Biddles Ltd, Guildford

Altringham JD (2011) Bats : from evolution to conservation. Oxford University Press

Arias-Aguilar A, Hintze F, Aguiar LMS, Rufray V, Bernard E, Pereira MJR (2018) Who's calling? Acoustic identification of Brazilian bats. Mammal Res 63(3):231-253

Bierregaard RO, Lovejoy TE (1990) Central Amazonian forests and the minimum critical size of ecosystems project. In: Gentry A (ed) Four Neotropical rain forests. Yale University Press, New Haven, pp 6074

Brinkløv S, Kalko EKV, Surlykke A (2009) Intense echolocation calls from two 'whispering' bats, Artibeus jamaicensis and Macrophyllum macrophyllum (Phyllostomidae). J Exp Biol 212: 11-20. https://doi.org/10.1242/jeb.023226
Brinkløv S, Jakobsen L, Ratcliffe JM, Kalko EKV, Surlykke A (2011) Echolocation call intensity and directionality in flying short-tailed fruit bats, Carollia perspicillata (Phyllostomidae). J Acoust Soc Am 129:427-435. https://doi.org/10.1121/1.3519396

Carreiras JMB, Jones J, Lucas RM, Gabriel C (2014) Land use and land cover change dynamics across the Brazilian Amazon: insights from extensive time-series analysis of remote sensing data. PLoS One 9: e104144. https://doi.org/10.1371/journal.pone.0104144

Clement MJ, Murray KL, Solick DI, Gruver JC (2014) The effect of call libraries and acoustic filters on the identification of bat echolocation. Ecol Evol 4:3482-3493. https://doi.org/10.1002/ece3.1201

Collen A (2012) The evolution of echolocation in bats: a comparative approach. University College London

Deichmann JL, Acevedo-Charry O, Barclay L, Burivalova Z, CamposCerqueira M, d'Horta F, Game ET, Gottesman BL, Hart PJ, Kalan AK, Linke S, Do Nascimento L, Pijanowski B, Staaterman E, Mitchell Aide T (2018) It's time to listen: there is much to be learned from the sounds of tropical ecosystems. Biotropica 50(5):713-718

Denzinger A, Schnitzler H-U (2013) Bat guilds, a concept to classify the highly diverse foraging and echolocation behaviors of microchiropteran bats. Front Physiol 4:164. https://doi.org/10. 3389/fphys.2013.00164

Denzinger A, Tschapka M, Schnitzler HU (2018) The role of echolocation strategies for niche differentiation in bats. Can J Zool 96(3): $171-181$

Farneda FZ, Rocha R, López-Baucells A, Groenenberg M, Silva I, Palmeirim JM, Bobrowiec PED, Meyer CFJ (2015) Trait-related responses to habitat fragmentation in Amazonian bats. J Appl Ecol 52:1381-1391. https://doi.org/10.1111/1365-2664.12490

Fenton MB, Acharya L, Audet D, Hickey MBC, Merriman C, Obrist MK, Syme DM, Adkins B (1992) Phyllostomid bats (Chiroptera: Phyllostomidae) as indicators of habitat disruption in the Neotropics. Biotropica 24:440. https://doi.org/10.2307/2388615

Ferreira DF, Rocha R, López-Baucells A, Farneda FZ, Carreiras JMB, Palmeirim JM, Meyer CFJ (2017) Season-modulated responses of Neotropical bats to forest fragmentation. Ecol Evol 7(11):4059 4071. https://doi.org/10.1002/ece3.3005

Flaquer C, Torre I, Arrizabalaga A (2007) Comparison of Sampling Methods for Inventory of Bat Communities. J Mammal 88(2): 526-533

Fleming TH (1989) The short-tailed fruit bat. A study in plant-animal interactions. J Trop Ecol 6:383. https://doi.org/10.1017/ S0266467400004703

Gessinger G, Gonzalez-Terrazas TP, Page RA, Jung K, Tschapka M (2019) Unusual echolocation behaviour of the common swordnosed bat Lonchorhina aurita : an adaptation to aerial insectivory in a phyllostomid bat? R Soc Open Sci 6:182165. https://doi.org/10. 1098/rsos. 182165

Giannini NP, Kalko EKV (2004) Trophic structure in a large assemblage of phyllostomid bats in Panama. Oikos 105:209-220. https://doi. org/10.1111/j.0030-1299.2004.12690.x

Gonzalez-Terrazas TP, Martel C, Milet-Pinheiro P, Ayasse M, Kalko EKV, Tschapka M (2016) Finding flowers in the dark: nectar-feeding bats integrate olfaction and echolocation while foraging for nectar. R Soc Open Sci 3(8):160199

Halfwerk W, Jones PL, Taylor RC, Ryan MJ, Page RA (2014) Risky ripples allow bats and frogs to eavesdrop on a multisensory sexual display. Sci 343:413-416. https://doi.org/10.1126/science.1244812

Handley CO, Wilson DO, Gardner AL (1991) Demography and natural history of the common fruit bat, Artibeus jamaicensis, on Barro Colorado Island, Panamá. Smithsonian Institution Press, Washington, DC

Hurtado N, Pacheco V, Hurtado-Miranda NE, Pacheco-Torres V (2014) Análisis filogenético del género Mimon Gray, 1847 (Mammalia, Chiroptera, Phyllostomidae) con la descripción de un nuevo género. Therya 5:751-791. https://doi.org/10.12933/therya-14-230 
Jennings NV, Parsons S, Barlow KE, Gannon MR (2004) Echolocation calls and wing morphology of bats from the West Indies. Acta Chiropterol 6:75-90. https://doi.org/10.3161/001.006.0106

Jones G (1999) Scaling of echolocation call parameters in bats. J Exp Biol 202:3359-3367

Jones G, Barlow K (2004) Cryptic species of echolocating bats. In: Thomas JA et al (eds) Echolocation in bats and dolphins. Chicago University Press, Chicago, pp 345-349

Jung J, Kim S-K, Kim JY, Jeong MJ, Ryu CM (2018) Beyond chemical triggers: evidence for sound-evoked physiological reactions in plants. Front Plant Sci 9:25. https://doi.org/10.3389/fpls.2018. 00025

Korine C, Kalko EKV (2005) Fruit detection and discrimination by small fruit-eating bats (Phyllostomidae): echolocation call design and olfaction. Behav Ecol Sociobiol 59:12-23. https://doi.org/10.1007/ s00265-005-0003-1

Krumbholz K, Schmidt S (2001) Evidence for an analytic perception of multiharmonic sounds in the bat, Megaderma lyra, and its possible role for echo spectral analysis. J Acoust Soc Am 109:1705-1716. https://doi.org/10.1121/1.1354198

Kunz TH, Braun de Torrez E, Bauer D, Lobova T, Fleming TH (2011) Ecosystem services provided by bats. Ann N Y Acad Sci 1223:138. https://doi.org/10.1111/j.1749-6632.2011.06004.x

Laurance WF, Camargo JLC, Luizão RCC, Laurance SG, Pimm SL, Bruna EM, Stouffer PC, Bruce Williamson G, Benítez-Malvido J, Vasconcelos HL, van Houtan KS, Zartman CE, Boyle SA, Didham RK, Andrade A, Lovejoy TE (2011) The fate of Amazonian forest fragments: a 32-year investigation. Biol Conserv 144:56-67

Lee TE, Dominguez DJ (2000) Ametrida centurio. 1-4. https://doi.org/ $10.2307 / 0.640 .1 / 2600468$

Leiser-Miller LB, Santana SE (2020) Morphological diversity in the sensory system of phyllostomid bats: implications for acoustic and dietary ecology. Funct Ecol. https://doi.org/10.1111/1365-2435. 13561

López-Baucells A, Rocha R, Bobrowiec P et al (2016) Field guide to Amazonian bats. Instituto Nacional de Pesquisas da Amazonia, Manaus

MacSwiney González MC, Clarke FM, Racey PA (2008) What you see is not what you get: the role of ultrasonic detectors in increasing inventory completeness in Neotropical bat assemblages. J Appl Ecol 45(5):1364-1371

Marimuthu G, Habersetzer J, Leippert D (2010) Active acoustic gleaning from the water surface by the Indian false vampire bat, Megaderma lyra. Ethology 99:61-74. https://doi.org/10.1111/j.1439-0310.1995. tb01089.x

Monteiro LR, Nogueira MR (2011) Evolutionary patterns and processes in the radiation of phyllostomid bats. BMC Evol Biol 11:137. https://doi.org/10.1186/1471-2148-11-137

Norberg U, Fenton MB (1988) Carnivorous bats? Biol J Linn Soc

O'Farrell MJ, Miller BW, Gannon WL (1999) Qualitative identification of free-flying bats using the Anabat detector. J Mammal 80:11-23

Parlos JA, Timm RM, Swier VJ et al (2014) Evaluation of the paraphyletic assemblages within Lonchophyllinae, with description of a new tribe and genus. Occas Pap Museum Texas Tech Univ 320: $1-23$

Pech-Canche JM, Estrella E, López-Castillo DL et al (2011) Complementarity and efficiency of bat capture methods in a lowland tropical dry forest of Yucatán, Mexico Complementariedad y eficiencia de métodos de captura de murciélagos en una selva baja caducifolia de Yucatán, México. Rev Mex Biodivers 82:896-903
Pio DV, Clarke FM, MacKie I, Racey PA (2010) Echolocation calls of the bats of Trinidad, West Indies: is guild membership reflected in echolocation signal design? Acta Chiropterol 12:217-229. https:// doi.org/10.3161/150811010X504716

R Core Team (2018) R: A language and environment for statistical computing. R Foundation for Statistical Computing, Vienna, Austria. http://www.Rproject.org/

Rex K, Michener R, Kunz TH, Voigt CC (2011) Vertical stratification of Neotropical leaf-nosed bats (Chiroptera: Phyllostomidae) revealed by stable carbon isotopes. J Trop Ecol 27:211-222. https://doi.org/ 10.1017/S0266467411000022

Rocha PAD, Pereira AS, Silvestre SM et al (2017a) Consumption of leaves by Platyrrhinus lineatus (Chiroptera, Stenodermatinae): are these bats primarily frugivorous or broadly phytophagous? Zoology 121:44-48. https://doi.org/10.1016/J.ZOOL.2016.12.004

Rocha R, Ovaskainen O, López-Baucells A, Farneda FZ, Ferreira DF, Bobrowiec PED, Cabeza M, Palmeirim JM, Meyer CFJ (2017b) Design matters: an evaluation of the impact of small man-made forest clearings on tropical bats using a before-after-control-impact design. For Ecol Manag 401:8-16. https://doi.org/10.1016/j.foreco. 2017.06.053

Rocha R, López-Baucells A, Farneda FZ et al (2019) Second-growth and small forest clearings have little effect on the temporal activity patterns of Amazonian phyllostomid bats. Curr Zool:zoz042. https:// doi.org/10.1093/cz/zoz042

Russo D, Ancillotto L, Jones G (2018) Bats are still not birds in the digital era: echolocation call variation and why it matters for bat species identification. Can J Zool 96:63-78. https://doi.org/10.1139/cjz2017-0089

Rydell J, Arita HT, Santos M, Granados J (2002) Acoustic identification of insectivorous bats (order Chiroptera) of Yucatan, Mexico. J Zool 257:S0952836902000626. https://doi.org/10.1017/ S0952836902000626

Santana SE, Geipel I, Dumont ER, Kalka MB, Kalko EKV (2011) All you can eat: high performance capacity and plasticity in the common big-eared bat, Micronycteris microtis (Chiroptera: Phyllostomidae). PLoS One 6:e28584. https://doi.org/10.1371/journal.pone.0028584

Schaer J, Reeder DM, Vodzak ME et al (2015) Nycteria parasites of Afrotropical insectivorous bats. Int J Parasitol 45:375-384. https:// doi.org/10.1016/J.IJPARA.2015.01.008

Schmidt U, Schmidt C (1977) Echolocation performance of the vampire bat (Desmodus rotundus). Z Tierpsychol 45:349-358

Shi JJ, Rabosky DL (2015) Speciation dynamics during the global radiation of extant bats. Evolution 69(6):1528-1545

Shi L, Feng J, Liu Y, Ye GX, Zhu X (2009) Is food resource partitioning responsible for deviation of echolocation call frequencies from allometry in Rhinolophus macrotis? Acta Theriol (Warsz) 54:371382. https://doi.org/10.4098/j.at.0001-7051.099.2008

Silva CR, Bernard E (2017) Bioacoustics as an Important Complementary Tool in Bat Inventories in the Caatinga Drylands of Brazil. Acta Chiropterologica 19(2):409-418

Silva I, Rocha R, López-Baucells A, Farneda FZ, Meyer CF (2020) Effects of forest fragmentation on the vertical stratification of neotropical bats. Diversity 12(2):67. https://doi.org/10.3390/d12020067

Simmons NB, Cirranello AL (2019) Bat species of the world: a taxonomic and geographic database. http://batnames.org. Accessed 13 Sep 2019

Smith P (2008) Woolly false vampire. In: Mammals of Paraguay. pp 110

Torrent L, López-Baucells A, Rocha R, Bobrowiec PED, Meyer CFJ (2018) The importance of lakes for bat conservation in Amazonian 
rainforests: an assessment using autonomous recorders. Remote Sens Ecol Conserv 4:339-351. https://doi.org/10.1002/rse2.83

Vilar EM, Nunes H, Nascimento JL, Estrela PC (2015) Distribution extension of Ametrida centurio gray, 1847 (Chiroptera, Phyllostomidae): first record in the Brazilian Atlantic Forest. Check List 11:1503. https://doi.org/10.15560/11.1/1503

Wilkinson GS (1985) The social organization of the common vampire bat. Behav Ecol Sociobiol 17:111-121. https://doi.org/10.1007/ bf00299243

Wilkinson GS, Wenrick Boughman J (1998) Social calls coordinate foraging in greater spear-nosed bats. Anim Behav 55:337-350. https:// doi.org/10.1006/ANBE.1997.0557
Zepeda Mendoza ML, Xiong Z, Escalera-Zamudio M, Runge AK, Thézé J, Streicker D, Frank HK, Loza-Rubio E, Liu S, Ryder OA, Samaniego Castruita JA, Katzourakis A, Pacheco G, Taboada B, Löber U, Pybus OG, Li Y, Rojas-Anaya E, Bohmann K, Carmona Baez A, Arias CF, Liu S, Greenwood AD, Bertelsen MF, White NE, Bunce M, Zhang G, Sicheritz-Pontén T, Gilbert MPT (2018) Hologenomic adaptations underlying the evolution of sanguivory in the common vampire bat. Nat Ecol Evol 2:659-668. https://doi.org/10.1038/s41559-018-0476-8

Publisher's note Springer Nature remains neutral with regard to jurisdictional claims in published maps and institutional affiliations. 